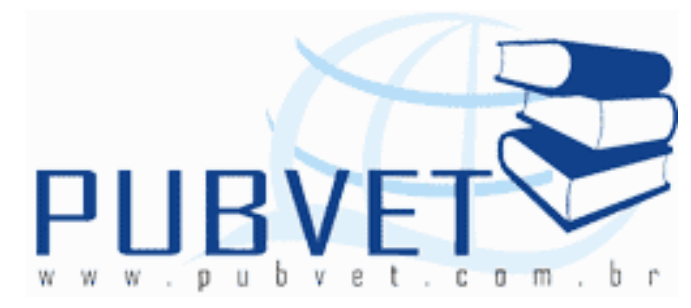

PUBVET, Publicações em Medicina Veterinária e Zootecnia.

\title{
Pododermatite em frangos de corte
}

Juliana Klug Nunes ${ }^{1}$, Liliane Novelini ${ }^{2}$, Bruna Strieder Kreuz ${ }^{3}$, Fabiane Pereira Gentilini $^{4}$, Marcos Antonio Anciuti ${ }^{4}$, Fernando Rutz ${ }^{5}$

${ }^{1}$ D.Sc., Médica Veterinária - Universidade Federal de Pelotas/RS

${ }^{2}$ Mestranda, Engenheira Agrônoma - Universidade Federal de Pelotas/RS

${ }^{3}$ Graduanda em Zootecnia, Universidade Federal de Viçosa/MG

4 Prof. D.Sc., Médico Veterinário - Instituto Federal Sul-Rio-grandense Campus Visconde da Graça (CaVG) - Pelotas/RS

${ }^{5}$ Prof. Ph.D., Médico Veterinário - Universidade Federal de Pelotas/RS

\section{Resumo}

A pesquisa bibliográfica teve por objetivo identificar as causas das lesões que levam à condenação dos pés de frangos de corte, uma vez que esse produto tem beneficiado a indústria avícola pelos crescentes mercados doméstico e internacional. A genética (alta taxa de crescimento, sexo, rápido ganho de peso), as deficiências nutricionais, e a ambiência (umidade da cama, amônia, temperatura, ventilação, umidade e época do ano) podem comprometer a imunidade das aves e predispor a ocorrência de lesões podais que poderão servir de porta de entrada para bactérias. Os mercados importadores classificam os pés e patas em três qualidades. As lesões no coxim plantar acompanhado de erosões e úlceras aumentam as perdas. 0 andar instável compromete o bem-estar e o desempenho zootécnico dos frangos de corte com condenações totais ou parciais na linha de abate. 
NUNES, J.K. et al. Pododermatite em frangos de corte. PUBVET, Londrina, V. 7, N. 11, Ed. 234, Art. 1545, Junho, 2013.

Embora, a pododermatite possa ser tratada, o melhor é evitá-la com correções nutricionais, ambientais e de manejo.

Palavras-chave: ambiente, aves, cama, criação, lesões, nutrição, pés, tratamento

\section{Pododermatitis in broilers}

\section{Summary}

The bibliographic search aimed to identify the causes of lesions leading the condemnation of the feet of broilers, since this product has benefited the poultry industry by increasing domestic and international markets. Genetics (high growth rate, sex, rapid weight gain), nutritional deficiencies, and ambience (litter moisture, ammonia, temperature, ventilation, humidity and time of year) can compromise the immunity of birds and predispose the patient to foot lesions that could serve as a gateway for bacteria. Markets importers classify the feet and legs in three qualities. The lesions in the footpad accompanied by erosions and ulcers increase the losses. The unsteady compromises the welfare and growth performance of broiler chickens with total or partial convictions on the slaughter line. Although the pododermatitis can be treated, it is best to avoid it fixes with nutritional, environmental and management.

Keywords: environment, birds, bed creation, injuries, nutrition, foot treatment.

\section{Introdução}

Na maioria dos países, os pés de frangos de corte são considerados um subproduto, porém na China é um corte de grande importância comercial, e mesmo com o crescimento da produção interna, a produção de pés de frango na China ainda é deficiente. Em 2010, à frente do Chile e da Argentina, o Brasil tornou-se o principal supridor do produto para o mercado chinês (AVISITE, 2010). 
NUNES, J.K. et al. Pododermatite em frangos de corte. PUBVET, Londrina, V. 7, N. 11, Ed. 234, Art. 1545, Junho, 2013.

Logo, a indústria avícola tem se beneficiado de crescentes mercados doméstico e internacional para os pés de frangos de corte, como uma commodity lucrativa (NRC, 2006). Assim sendo, a preocupação em identificar as lesões que levam à condenação dos pés tem aumentado (SANTOS et al., 2002).

\section{Descrição e causas de pododermatite}

A seleção genética dos frangos de corte para alta taxa de crescimento e rápido ganho de peso é acompanhada pela diminuição da capacidade de locomoção (KESTIN et al., 2001). Além disso, a alta densidade de alojamento, que acarreta maior excreção e maior pressão sobre a cama, o que pode torná-la compactada e úmida (MENZIES et al., 1997; DAWKINS et al., 2004; DOZIER et al, 2005), as condições inadequadas da cama utilizada para a criação das aves, como o excesso de umidade, a falta de higiene nos galpões de criação, o estresse que reduz a imunidade das aves, os traumatismos e a deficiência de nutrientes na alimentação, entre eles, de biotina, são fatores predisponentes para a ocorrência de pododermatite (HARNS et al., 1977; GREENE et al., 1985; MARTRENCHAR et al., 1997; RUPLEY, 1999; SAIF, 2005).

Estudo desenvolvido por Dawkins et al. (2004) indicou que, apesar de densidades muito elevadas afetarem o bem-estar dos frangos de corte, existem outros fatores importantes no ambiente das aves, tais como tamanho do galpão e idade, umidade da cama, amônia do ar, temperatura, ventilação, umidade e época do ano que desempenham um papel importante na etiologia da pododermatite.

A pododermatite pode ser citada como o maior fator limitante da qualidade dos pés de frangos para a exportação, pois dependendo do grau da lesão, leva a depreciação do produto com o corte para retirada da lesão ou mesmo o descarte total (SANTOS et al., 2002). 
NUNES, J.K. et al. Pododermatite em frangos de corte. PUBVET, Londrina, V. 7, N. 11, Ed. 234, Art. 1545, Junho, 2013.

A pododermatite é um tipo de dermatite de contato caracterizada por uma inflamação cutânea do coxim plantar das aves, podendo afetar também os coxins digitais. Ela se inicia por um fator abrasivo, formando lesão eritematosa e pruriginosa, e com avanço dos sinais clínicos torna-se exudativa e ulcerativa, com infecção bacteriana primária ou secundária (COOPER \& HARRISON, 1999; SAIF, 2005). A hiperqueratose e a necrose da epiderme podem se desenvolver, e em casos graves, estas mudanças são seguidas por ulcerações com reações inflamatórias do tecido subcutâneo (EKSTRAND et al., 1997). Quando presentes, as ulcerações, frequentemente, são cobertas por crostas formadas por exsudato, cama e material fecal (GREENE et al. 1985).

As lesões de pododermatite podem se instalar em períodos inferiores a uma semana evoluindo para ulcerações (GREENE et al., 1985); e essas lesões podem também ser denominadas de queimadura por amônia, uma vez que a sua causa pode estar associada a umidade e ao alto conteúdo de amônia presente na cama dos aviários (BERG, 1998).

A severidade da dermatite podal é um aspecto importante do bemestar de aves (ALGERS \& BERG, 2001; HASLAM et al., 2006) e em casos graves pode causar dor (BERG, 1998), resultando em andar instável com comprometimento do desenvolvimento das aves, por restringir o acesso ao alimento e à água (HESTER, 1994). Histologicamente pode ser observada inflamação aguda com necrose na lesão, podendo haver detritos celulares e bactérias na epiderme, e em casos graves, pode afetar a derme (SAIF, 2005).

Em Psittaciformes e Passeriformes, as causas mais frequentes de lesões podais são de caráter bacteriano, tendo a má nutrição como fator predisponente (RUPLEY, 1999) e o principal agente isolado o Staphyloccocus aureus (GUIMARÃES, 2006). Anderson (1983) relatou que a estafilococose é mais comum em aves criadas em gaiolas ou em pisos ásperos e pontiagudos, pois, nestas condições, os coxins plantares podem apresentar 
NUNES, J.K. et al. Pododermatite em frangos de corte. PUBVET, Londrina, V. 7, N. 11, Ed. 234, Art. 1545, Junho, 2013.

ulcerações, abrindo uma porta de entrada para o S. aureus presente na cama aviária ou nas fezes.

De acordo com o anexo IX da Portaria no 210 do Ministério da Agricultura, Pecuária e Abastecimento (BRASIL, 1998), a pododermatite está enquadrada dentro dos critérios e destinos de aves com dermatoses, sendo, portanto, uma lesão de caráter condenatório, ou da região atingida ou de toda a pata. Porém, os pés e patas, no Brasil, são classificados apenas quanto a sua qualidade e levam em consideração as condições impostas pelos mercados importadores. Para estes a seleção se enquadra em três especificações: patas e pés de melhor qualidade são aqueles que não apresentam lesões; os de segunda qualidade apresentam lesões não muito extensas, e os com muitas lesões de qualquer natureza que são destinados à graxaria.

Pagazaurtundua \& Warriss (2006) definiram, fotograficamente, através da análise do percentual de acometimento do coxim plantar, uma escala de quatro pontos. Nesta escala, os pés que recebem o escore 0 não possuem lesões, os de escore 1 apresentam lesões brandas, uma pequena área da pele foi atingida, os de escore 2 possuem lesões severas e os pés classificados como 3 são os afetados de forma grosseira.

Rotineiramente, o diagnóstico de pododermatite é realizado pela observação de um ponto marrom enegrecido na face plantar do pé da ave e este é facilmente visualizado com a retirada da cutícula dos pés, na linha de abate (BERG, 1998).

Santos et al. (2002) relataram que a descoloração do coxim plantar, estágio inicial da doença, pouco interfere na forma de comercialização do corte, mas quando as erosões e úlceras começam a se formar, há uma grande perda da qualidade, que dependendo de sua extensão ainda é possível ser feito um aproveitamento parcial dos pés e das patas. 
NUNES, J.K. et al. Pododermatite em frangos de corte. PUBVET, Londrina, V. 7, N. 11, Ed. 234, Art. 1545, Junho, 2013.

\section{Condições de cama e material de cama}

O contínuo contato da ave com a cama exige que o que o material utilizado seja de qualidade adequada, sendo capaz de modificar as características do meio, proporcionando conforto aos animais e melhor desempenho zootécnico (AVILA et al., 1992).

Os níveis de umidade na cama do aviário superior a 35\% têm efeitos negativos na saúde das aves, frequentemente, resultando em pododermatites (MAYNE et al., 2006; HASLAM et al., 2006), foliculites e enterites necróticas (EKSTRAND et al., 1997). A umidade também aumenta a taxa de produção de $\mathrm{NH}_{3}$ (BROOM \& REEFMANN, 2005).

Os níveis de $\mathrm{NH}_{3}$ abaixo de $10 \mathrm{ppm}$ podem prejudicar o desempenho e a imunidade das aves, aumentando a susceptibilidade a infecções respiratórias (KESTIN \& SORENSEN, 1999; BILGILI et al., 2009). Já os níveis de $\mathrm{NH}_{3}$ acima de $10 \mathrm{ppm}$ liberados da cama do aviário causam irritação grave do trato respiratório e da pele das aves, resultando em pododermatite, queimaduras do jarrete, e lesões no peito (MARTRENCHAR et al., 2002).

O ácido propiônico, o fosfato de cálcio monobásico, o ácido fosfórico, o sulfato ferroso, o cloreto de alumínio, o permanganato de potássio, a argila e o bissulfato de sódio têm sido usados com sucesso para reduzir o $\mathrm{pH}$ da cama de aviários, a volatilização da amônia e inibir a carga microbiana presente na cama (MARSMAN et al., 1997; MATHLOUTHI et al., 2002; GRACIA et al., 2003).

$\mathrm{O} \mathrm{NaHSO}_{4}$ é facilmente solúvel em água e uma solução aquosa a $5 \%$ tem um $\mathrm{pH}<1$. Pesquisas com o uso de $\mathrm{NaHSO}_{4}$ em cama de aviário mostraram melhor desempenho de frangos de corte (MUKRAMI et al., 2000; BILGILI, et al, 2009).

Nagaraj et al. (2006) afirmaram que o conteúdo de $\mathrm{NH}_{3}$ na cama do aviário tem efeito significativo sobre a pododermatite em frangos de corte e analisaram a eficácia de $\mathrm{NaHSO}_{4}$ sobre a volatização do $\mathrm{NH}_{3}$ e a redução das 
NUNES, J.K. et al. Pododermatite em frangos de corte. PUBVET, Londrina, V. 7, N. 11, Ed. 234, Art. 1545, Junho, 2013.

lesões nos coxins plantares de frangos de corte alimentados com dietas à base de vegetais e com alto teor de proteína e concluíram que o $\mathrm{NaHSO}_{4}$ teve um efeito significativo $(\mathrm{P}<0,05)$ sobre a volatilização de $\mathrm{NH}_{3}$, até 35 dias de idade das aves, e que a incidência de pododermatite reduziu numericamente com o uso de $\mathrm{NaHSO}_{4}$. Os autores supõem que os baixos níveis de umidade da cama suprimiram o efeito higroscópico do $\mathrm{NaHSO}_{4}$ e que a variabilidade das taxas de ventilação também podem ter afetado os níveis de $\mathrm{NH}_{3}$ volatilizado.

O sistema de bebedouro influência na umidade da cama e na incidência de pododermatite De acordo com Mayne (2005), o uso de bebedouros do tipo copo e nipple reduzem as condições de cama molhada quando comparado com os bebedores do tipo pendular.

Martland (1985) enfatiza a umidade da cama na etiologia da pododermatite, pois ao transferir aves de uma cama molhada para cama de areia seca observou cura das lesões de pododermatite.

Mayne et al. (2006) relataram que papelão e palha, devido à sua baixa eficiência para absorver umidade, são materiais com menor preferência como cama para aviário.

Baere et al. (2009) avaliaram a utilização de cama de maravalha ou de palha picada sobre a incidência de pododermatite em frangos de corte e verificaram que as aves criadas sobre cama de palha picada tiveram mais lesões de queima de jarrete e pododermatite; sendo estas mais observadas aos 28,35 e 41 dias de idade.

Já Bilgili et al. (2009) observaram que o uso de areia como material de cama reduz a incidência e a gravidade de pododermatite em frangos de corte em comparação ao uso de cama de maravalha de pinho.

\section{Sistema de criação}

Pagazaurtundua \& Warriss (2006) avaliaram os sistemas de criação de frangos de corte associados com a ocorrência de pododermatite e 
NUNES, J.K. et al. Pododermatite em frangos de corte. PUBVET, Londrina, V. 7, N. 11, Ed. 234, Art. 1545, Junho, 2013.

verificaram que em sistemas de criação padrão a prevalência foi de 14,8\%, já nos sistemas livres e orgânicos a incidência foi bem maior chegando a $98,1 \%$ no sistema de criação orgânico.

Em poedeiras, a literatura descreve uma grande variedade de lesões de patas, que vão desde hiperqueratose leve a lesões de pododermatite (WANG et al., 1998). Hiperqueratose e dobras de garras inflamadas e inchadas são condições presentes na maioria das vezes no bloco distal do dedo do pé de aves alojadas em gaiolas (SVEDBERG, 1988).

\section{Densidade de alojamento, peso e sexo das aves e idade de} abate

Em criações de alta densidade e em linhagens de crescimento rápido, a pododermatite, em alguns casos, é o problema predominante (DAWKINS et al., 2004).

$\mathrm{Na}$ segunda e quarta semana de idade uma densidade de 16 e 20 aves $/ \mathrm{m}^{2}$, representa cerca de 5 e $8 \mathrm{~kg} / \mathrm{m}^{2}$, respectivamente, e além de trazer desconforto nas primeiras semanas de vida da ave, reduz o bem-estar na fase final de crescimento, pois restringe a locomoção e causa aumento da superfície de contato da ave com a cama, aumentando assim a ocorrência da dermatite de contato (ANDREWS et al., 1997).

Martrenchar et al. (1997) observaram uma correlação direta entre a incidência de pododermatite e a degradação da cama do aviário, devido à alta densidade animal, que leva a redução da circulação de ar no aviário e ao aumento da incidência de lesões e hematomas nas aves.

Sorensen et al. (2000) relataram que aves mais pesadas são mais afetadas com queimaduras nos joelhos, indicando uma correlação positiva com o peso corporal, e que aves alojadas em altas densidades (22 aves $/ \mathrm{m}^{2}$ ) apresentaram maior incidência de queimaduras nos joelhos e pés quando comparadas com aquelas alojadas em menor densidade $\left(16\right.$ aves $\left./ \mathrm{m}^{2}\right)$. Isso ocorre, principalmente, na fase final de criação, pois com o espaço reduzido 
NUNES, J.K. et al. Pododermatite em frangos de corte. PUBVET, Londrina, V. 7, N. 11, Ed. 234, Art. 1545, Junho, 2013.

a ave pouco se locomove e acaba passando a maior parte do tempo abaixada com os joelhos e pés em contato com a cama (OLIVEIRA et al., 2004).

Martrenchar et al. (2002) avaliaram fatores relacionados ao galpão, cama e densidade de alojamento e no abatedouro pontuaram as lesões observadas no coxim plantar de frangos de corte e de perus em escore 0 (ausência de lesão), 2 (lesão moderada) e 3 (lesão grave). No lote de frangos de corte, $80 \%$ das aves apresentaram escore 0 e relacionaram 0 resultado ao uso de pisos de concreto com cama de maravalha. Em perus, $48 \%$ das fêmeas e $46 \%$ dos machos apresentaram lesões de patas, sendo mais de $10 \%$ classificadas com o escore 3 e atribuíram a observação ao sistema de ventilação deficiente $\left(<150 \mathrm{~m}^{3} / \mathrm{h} / \mathrm{kg}\right.$ ). Os autores também verificaram que a densidade de alojamento não teve influência sobre a prevalência de pododermatite em frangos de corte.

Da mesma forma, Oliveira \& Carvalho (2002) não verificaram efeito da densidade populacional (10, 12 e 15 aves/m²) sobre as lesões de peito, joelho ou coxim plantar. Já Oliveira et al. (2004) verificaram que a densidade populacional, 14, 16 e 18 aves $/ \mathrm{m}^{2}$, e o sexo influenciaram $(P<$ $0,01)$ a incidência de lesões nos joelhos e no coxim plantar de frangos de corte, sendo que as aves criadas na densidade mais alta apresentaram lesões no coxim plantar mais severas $(3,25)$ do que aquelas criadas nas menores densidades $(2,50$ e 2,63) e os machos apresentaram lesões mais severas do que as fêmeas $(1,91 \times 1,34$ e 2,12 x 1,33, respectivamente, para joelho e coxim plantar em machos e fêmeas).

Bessei (2006) também observou que a densidade populacional elevada aumentou a incidência de lesões de pododermatite, em particular com $30 \mathrm{~kg}$ de peso vivo/m2, porém Grashorn \& Kutritz (1991) afirmaram que taxas de ventilação aumentadas podem aliviar este efeito negativo.

Os machos tendem a ser mais pesados, logo estabelecem maior contato com a cama, principalmente de joelhos e coxins plantares, tornando-a mais compactada com pouca absorção de umidade, além disso, 
NUNES, J.K. et al. Pododermatite em frangos de corte. PUBVET, Londrina, V. 7, N. 11, Ed. 234, Art. 1545, Junho, 2013.

geram maior quantidade de excretas do que as fêmeas, o que torna a cama mais úmida (OLIVEIRA et al., 2004).

Cravener et al. (1992) relataram que os machos tiveram uma maior percentagem (12\%) de calos de peito do que as fêmeas (5\%). Segundo Ekstrand (1993), a dermatite de contato é mais comum em lotes de machos, e isso é atribuído ao maior peso e ao pior empenamento dos machos, o que aumenta o grau de exposição da pele à cama.

Angelo et al. (1997) observaram que frangos de corte machos apresentaram escores superiores aos das fêmeas para calos nos joelhos (0,99 x 0,78, respectivamente para machos e fêmeas), não havendo diferenças quanto aos escores de calo de peito e de coxim plantar.

Alley et al. (1998) observaram que a incidência e a severidade das lesões no coxim plantar foram maiores em machos do que em fêmeas. Já Berg (1998) não encontrou diferença entre os sexos para dermatite de contato.

Kjaer et al. (2006) realizaram experimento utilizando machos e fêmeas de uma linhagem de frangos de corte de crescimento rápido e de uma linhagem de crescimento lento para avaliar dermatite de contato. Os autores observaram que as fêmeas foram mais afetadas (49 versus 36\%, $\mathrm{P}$ $<0,05)$ e que nas aves de crescimento rápido as lesões de dermatite apareceram às duas semanas de idade e tenderam a aumentar semanalmente até 6 semanas de idade. Relataram uma herdabilidade de $0,31 \pm 0,12$ para a dermatite de contato, indicando que esta pode ser diminuída pela seleção genética. A correlação genética para peso corporal e dermatite foi baixa e não significativa, assim como a correlação fenotípica entre peso corporal e dermatite de contato. Logo, a seleção para maior ganho de peso pode não afetar a suscetibilidade genética para o desenvolvimento da dermatite de contato. A herdabilidade alta da dermatite e a baixa correlação genética para ganho de peso sugeriram que a seleção genética contra a susceptibilidade a dermatite é possível sem efeitos negativos sobre o ganho de peso vivo. 
NUNES, J.K. et al. Pododermatite em frangos de corte. PUBVET, Londrina, V. 7, N. 11, Ed. 234, Art. 1545, Junho, 2013.

No estudo de Nagaraj et al. (2006), as fêmeas de frangos de corte apresentaram maior incidência de pododermatite em relação aos machos ( $P$ $<0,05)$ e que os machos apresentaram maior proporção de lesões graves em comparação as fêmeas. Os autores relataram que isso ocorreu por terem as fêmeas menor matriz de colágeno na pele do que os machos, o que torna a pele mais propensa a lesões e ulceração.

Sorensen et al. (2000) encontraram maior grau de dermatite de contato em frangos de corte abatidos entre 33-35 dias de idade ao comparar com aves abatidas entre 35-45 dias de idade. Da mesma forma, Ekstrand et al. (2007) observaram que aves abatidas em idade mais avançada apresentaram menor condenação de patas no abatedouro e atribuíram isso a cicatrização das lesões.

\section{Nutrição}

A ocorrência de pododermatite também tem sido associada a deficiências de biotina (HARMS \& SIMPSON, 1975), metionina (CHAVEZ \& KRATZER, 1972), cistina (MURILLO \& JENSEN, 1975) e zinco (HESS et al., 2001).

De acordo com Harms \& Simpson (1975) o mecanismo biológico da variação genética da pododermatite pode estar relacionada à biotina, componente funcional de vários sistemas enzimáticos, ou seja, as aves suscetíveis podem ter a função de absorção perturbada, por alteração genética da fisiologia do intestino que influencia a flora microbiana, ou estarem recebendo dietas com deficiência marginal dessa vitamina.

Outro fator que leva a incidência da dermatite de contato por deficiência de biotina, em frangos de corte, é a inoculação de Lactobacillus acidophilus, pois estes micro-organismos competem pela biotina dietética (BUENROSTRO \& KRATZER, 1983). 
NUNES, J.K. et al. Pododermatite em frangos de corte. PUBVET, Londrina, V. 7, N. 11, Ed. 234, Art. 1545, Junho, 2013.

Assim sendo, a suplementação de biotina nas matrizes resultaria em um aumento no nível de biotina em ovos e em uma diminuição da dermatite de contato na progênie (HARMS et al., 1979).

A inclusão de farelo de soja como principal fonte de proteína tem recebido atenção, pois este ingrediente é naturalmente deficiente em biotina (WHITEHEAD \& BANNISTER, 1981) e possui polissacarídeos não-amídicos na sua composição, o que é apontado como um fator que causa fezes pegajosas e úmidas (BOLING \& FIRMAN, 1997; BILGILI et al., 2006a).

Os polissacarídeos não-amídicos dificultam a digestibilidade dos lipídios, proteínas e amido e também reduzem a absorção de nutrientes (ANNISON, 1993). Em aves jovens, as quantidades limitadas de enzimas endógenas limitam a digestibilidade das dietas ricas em proteínas vegetais e carboidratos (NOY \& SKLAN, 1994). Logo, a suplementação de enzimas exógenas pode melhorar a digestão quebrando os polímeros, inativando os fatores antinutricionais, complementando a ação das enzimas endógenas, manipulando a microflora intestinal e reduzindo a viscosidade da digesta (MALATHI \& DEVEGOWDA, 2001).

Nagaraj et al. (2006) avaliaram a utilização de dietas à base de vegetais e à base de vegetais e produtos de origem animal, com alto ou baixo nível de proteína, com ou sem suplementação de 0,06\% de complexo enzimático (Allzyme VegPro) e verificaram que os níveis de proteína não influenciaram as lesões de pododermatite e que a suplementação enzimática nas dietas à base de vegetais reduziu a incidência de lesões de pododermatite aos 57 dias de idade dos frangos de corte. Os níveis de nitrogênio amoniacal foram afetados pelo nível de proteína na dieta (alto > baixo), pela fonte de proteína (vegetal > vegetal + animal) e pela suplementação enzimática (com enzima > sem enzima).

O uso de dietas comerciais formulados com alta densidade de nutrientes (BILGILI et al., 2006a) e sal (MUKRAMI et al., 2000) pode resultar em maior incidência de pododermatite. 
NUNES, J.K. et al. Pododermatite em frangos de corte. PUBVET, Londrina, V. 7, N. 11, Ed. 234, Art. 1545, Junho, 2013.

No farelo de soja, o alto conteúdo de potássio pode levar ao desequilíbrio de eletrólitos na dieta das aves e ao maior consumo de água, ocasionando problema de cama úmida e consequentemente de pododermatite (BOLING \& FIRMAN, 1997).

Whitehead \& Bannister (1981) observaram que o alto teor de proteína na dieta afetou negativamente a disponibilidade plasmática de biotina e a qualidade da pele das aves, o que levou a pododermatite.

O aumento no nível de proteína na dieta causa sobrecarga de ácido úrico nos rins, excessiva excreção de nitrogênio, altos níveis de amônia na cama do aviário e condições de cama molhada, fator predisponente a fermentação e aumento de temperatura da cama, o que causa lesões no coxim plantar (GORDON et al., 2003).

O zinco está envolvido no processo de formação da queratina, do colágeno e na síntese de ácido nucleico da pele. Oliveira et al. (2010), utilizaram 27 ppm de zinco orgânico em dieta isocalórica e isoproteica para frangos de corte para avaliar a prevenção da pododermatite e concluíram que a adição de $\mathrm{Zn}$ orgânico melhorou a queratinização da pele e contribuiu para reduzir o grau de pododermatite nos frangos de corte, isso ocorreu porque os minerais na forma orgânica, complexados a um aminoácido, dipeptídeos, tripeptídeos ou proteínas, apresentam melhor digestibilidade e biodisponibilidade intestinal quando comparados às formas inorgânicas (LEESON, 2003).

O zinco interfere na regulação de genes, mantém a saúde do tecido epitelial, promove a integridade da pele, sua reparação e proteção, e desta foram reduz as perdas econômicas por descarte de patas a nivel de abatedouro. Outra função do zinco é o desenvolvimento, manutenção e funcionamento de células que interferem na resposta imune, como macrófagos, linfócitos T, basófilos e heterofilos. (KIDD et al., 1996). O manganês, por sua vez, atua no metabolismo dos carboidratos e dos lipídios e na regulação da taxa de crescimento, assim como no desenvolvimento de 
NUNES, J.K. et al. Pododermatite em frangos de corte. PUBVET, Londrina, V. 7, N. 11, Ed. 234, Art. 1545, Junho, 2013.

ossos e no crescimento da matriz óssea. O manganês também atua no empenamento e na reprodução (KLASING, 1998).

Sanabria \& Morales (2008) avaliaram o efeito do complexo zincomanganês-metionina, adicionado a dieta, na concentração de 40 ppm de cada oligoelemento, sobre a incidência de pododermatite em frangos de corte provenientes ou não de matrizes que também receberam o complexo via ração, e observaram que $74,56 \%$ das aves, filhas de matrizes tratadas e que receberam o complexo na ração, não apresentaram lesões

\section{Tratamento}

A pododermatite, uma vez instalada, se não for devidamente tratada, evolui causando danos aos membros da ave, o que dificulta a busca por alimento, o conforto da ave ao ficar em estação e sobre o poleiro, a locomoção, podendo debilitá-la a ponto de proporcionar septicemia e morte (RUPLEY, 1999). Ao ocorrerem sequelas como necroses, perda de funcionalidade do dígito ou do membro inteiro, perda da garra do dígito afetado, há comprometimento da qualidade de vida da ave (KELECOM, 2008).

Há vários graus de severidade para as lesões de pododermatite, e isto influenciará no tratamento e na duração do tratamento a ser utilizado (RUPLEY, 1999). Em lesões mais leves, o tratamento é realizado com escarificação com escova cirúrgica, antissépticos locais, pomadas a base de lanolina e cicatrizantes. Também são preconizadas, a correção e a higienização de poleiros e o manejo alimentar. As lesões mais graves precisam ser avaliadas radiologicamente quanto à presença de osteomielite e debridação dos abcessos presentes. Além disto, é importante a utilização de anti-inflamatórios locais e antibioticoterapia sistêmica (RUPLEY, 1999).

Segundo Cooper \& Harrison (1999) as lesões por Staphyloccocus spp. devem ser tratadas com associação de antibióticos tópicos e sistêmicos, além do uso de anti-inflamatórios esteroidais tópicos. Como curativo é 
NUNES, J.K. et al. Pododermatite em frangos de corte. PUBVET, Londrina, V. 7, N. 11, Ed. 234, Art. 1545, Junho, 2013.

recomendado o do tipo atadura em esfera, onde se usa tampão de gaze embebida em iodo-povidona estéril ou clorexidina envolto com atadura que fecha os dígitos da ave sobre a esfera de gaze. Também pode utilizar-se pomada contendo antibióticos e anti-inflamatórios tópicos, como gentamicina e valerato de betametasona. A troca de curativos deve ser procedida a cada 24 - 48h e o ambiente onde a ave se encontra deve ser realizada diariamente (RUPLEY, 1999).

No caso de lesões unilaterais, o membro não afetado deve ser diariamente monitorado, pois ocasionalmente forma-se pododermatite em função do aumento da sustentação do peso da ave em um único membro (RUPLEY, 1999).

Com relação a qual antibiótico usar no tratamento, Rupley (1999) recomenda o uso de enrofloxacina, piperaciclina ou carbenicilina, enquanto Guimarães (2006) recomenda o uso de antibióticos da família das cefalosporinas devido à resistência que o micro-organismo Staphyloccocus spp. vem apresentando. Porém em um ponto todos concordam: estas sugestões são apenas para tratamento inicial, sendo recomendada a realização de cultura e de antibiograma das lesões a fim de optar-se pelo melhor antibiótico para cada caso.

Juntamente com o tratamento medicamentoso deve ser realizada correção nutricional, de manejo e higienização do ambiente (KELECOM, 2008).

\section{Considerações finais}

Não há uma única causa para a pododermatite que compromete tanto os pés e as patas das aves como também o bem-estar e o desempenho zootécnico com consequentes descartes totais ou parciais na linha de abate de frangos de corte.

Embora possa ser tratada, o melhor é evitar a pododermatite com correções nutricionais, ambientais e de manejo. 


\section{REFERÊNCIAS}

ALGERS, B.; BERG, C. Monitoring animal welfare on commercial broiler farms in Sweden. Acta Agriculturae Scandinavica, Section Animal Science, v.30, p.88-92, 2001.

ALLEY, M.A.; BILGILI, S.F.; MORAN, E.T.; HESS, J.B. Quality and yields of broiler feet as influenced by strain-cross, sex and feeding programs. In: ANNUAL MEETING, 87, 1998, Pennsylvania, Proceedings... Pennsylvania, 1998, p.79.

ANDERSON, J.C. Veterinary aspects of staphilococci. In: EASMON, C.S.F.; ADLAM, C. (Eds.). Staphylococci and staphylococcal infections. London Academic Press, 1983, p.193-241.

ANDREWS, S.M.; OMED, H.M.; PHILLIPS, C.J.C. The effect of a single or repeated period of high stocking density on the behavior and response to stimuli in broiler chickens. Poultry Science, v.76, p.1655-1660, 1997.

ANGELO, J.C. de; GONZALES, E.; KONDO, N., ANZAI, N.H.; CABRAL, M.M. Material de cama: qualidade, quantidade e efeito sobre o desempenho de frangos de corte. Revista Brasileira de Zootecnia, v.26, n.1, p.121-130, 1997.

ANNISON, G. The role of wheat non-starch polysaccharides in broiler nutrition. AUSTRALIAN JOURNAL OF AGRICULTURAL, v.44, p.405-422, 1993.

AVILA, V.S.; MAZZUCO, H.; FIGUEIREDO, E.A.P. Cama de aviário: materiais, reutilização, uso como alimento e fertilizante. Concórdia: EMBRAPA - CNPSA, 1992. 38p.

AVISITE - O Portal da Avicultura na Internet. Notícias: Exportação de patas de frango dos EUA recua quase à metade. 2010. Disponível em: http://www.avisite.com.br/notícias. Acesso em: setembro de 2011.

BAERE, K. de; COX, M.; VERVAET, E.; ZOONS, J.; FIKS-Van NIERKEK, T. Effect of litter material on foot little influence on the live performance as also reported pad dermatitis and hock burn in broilers. In: $8^{\text {th }}$ EUROPEAN SYMPOSIUM ON POULTRY WELFARE, 2009, Cervia, Italy, Proceedings... Cervia, 18-22 may, 2009, p.52.

BERG, C. Footpad dermatitis in broilers and turkeys - prevalence, risk factors and prevention. 1998. 36f. PhD thesis - Swedish Univeristy of Agricultural Sciences, Uppasala, Sweden. Acta Universitatis Agriculturae Sueciae, Veterinaria, Sueciae.

BESSEI, W. Welfare of broilers: a review. World's Poultry Science Journal, v.62, p.455466, 2006.

BILGILI, S.F.; ALLEY, M.A.; HESS, J.B.; MORAN JR., E.T. Influence of strain-cross, sex and feeding programs on broiler chicken paw (feet) yield and quality. In: $17^{\text {th }}$ EUROPEAN SYMPOSIUM ON THE QUALITY OF POULTRY MEAT. 2006, World's Poultry Science Association, Beekbergen, the Netherlands. Proceedings ... Netherlands, 2006. p.342349a.

BILGILI, S.F.; ALLEY, M.A.; HESS, J.B.; NAGARAJ, M. L. Influence of age and sex on footpad quality and yield in broiler chickens reared on low and high density diets. Journal of Applied Poultry Research, v.15, p.433-441, 2006 b.

BILGILI, S.F.; HESS, J.B.; BLAKE, J.P.; MACKLIN, K.S.; SAEMAHAYAK, B. SIBLEY, J.L. Influence of bedding material on footpad dermatitis in broiler chickens. Journal of Applied Poultry Research, v.18, p.583-589, 2009. 
BOLING, S.D.; FIRMAN, J.D. Rendered by-products as soybean meal replacement in turkey rations. Journal of Applied Poultry Research, v.6, p.210-215, 1997.

BRASIL, Ministério da Agricultura, Pecuária e Abastecimento. Portaria $\mathrm{n}^{\circ} 210$, de 10 de novembro de 1998. Ementa: Aprovar o Regulamento Técnico da Inspeção Tecnológica e Higiênico-Sanitária de Carne de Aves. Diário Oficial da União, Brasília, DF, seção 1, p.226, 26 de novembro de 1998.

BROOM, D.M.; REEFMANN, N. Chicken welfare as indicated by lesions on carcass in supermarkets. British Poultry Science, v.46, p.407-414, 2005.

BUENROSTRO, J.L.; KRATZER, F.H. Effect of Lactobacillus inoculation and antibiotic feeding of chickens on availability of dietary biotin. Poultry Science, v.62, p.2022-2029, 1983.

CHAVEZ, E.; KRATZER, F.H. Preventive of foot pad dermatitis in poults with methionine. Poultry Science, v.51, p.1545-1548, 1972.

COOPER, J.E.; HARRISON, G.J. Dermatology. In: RITCHIE, B.W.; HARRISON, G.J.; HARRISON, L.R. Avian Medicine: Principles and application. Flórida: Wingers Publishing, 1994. Cap. 24, p.607-632, 1999.

CRAVENER, T.L.; ROUSH, W.B.; MASHALY, M.M. Broiler production under varying population densities. Poultry Science, v.71, p.427-433, 1992.

DAWKINS, M.S.; DONNELLY, C.A.; JONES, T.A. Chicken welfare is influenced more by housing conditions than by stocking density. Nature, v.427, p.342-344, 2004.

DOZIER, W.A.; THAXTON, J.P.; BRANTON, S.L.; MORGAN, G.W.; MILES, D.M.; ROUSH, W.B.; LOTT, B.D.; VIZZIER-THAXTON, Y. Stocking density effects on growth performance and processing yields of heavy broilers. Poultry Science, v.84, p.1332-1338, 2005.

EKSTRAND, C. Effects of stocking density on the health, behavior and productivity of broilers. A literature review. Skara: Faculty of Veterinary Medicine, 1993. 46 p. (Rapport 32).

EKSTRAND, C.; ALGERS, B.; SVEDBERG, J. Rearing conditions and foot-pad dermatitis in Swedish broiler chickens. Preventive Veterinary Medicine, v.31, p.167-174, 1997.

GORDON, S.H.; WALKER, A.W.; CHARLES, D.R. Feeding and broiler welfare. In: Symposium Measuring and Auditing Broiler Welfare - A Practical Guide. 2003, Inglaterra. Proceedings ... Inglaterra: University of Bristol, UK, 2003. p.19.

GRACIA, M.I.; ARANÍBAR, M.J.; LÁZARO, R.; MEDEL, P.; MATEOS, G.G. a-Amylase supplementation of broiler diets based on corn. Poultry Science, v.82, p.436-442, 2003.

GRASHORN, M.; KUTRITZ, B. Effect of stocking density on performance of modern broiler breeds. Archiv Für Geflügelkunde, v.55, n.2, p.84-90, 1991.

GREENE, J.A.; MCCRACKEN, R.M.; EVANS, R.T. Contact dermatitis of broilers - clinical and pathological findings. Avian Pathology, v.14, p.23-38, 1985.

GUIMARÃES, M.B. In: CUBAS, Z.S.; SILVA, J.C.; CATÃO-DIAS, J.L. Tratado de animais selvagens. São Paulo: Roca, 2006, p.324-339.

HARMS, R.H.; SIMPSON, C.F. Biotin deficiency as a possible cause of swelling and ulceration on foot pads. Poultry Science, v.54, n.5, p.1711-1713, 1975. 
HARMS, R.H.; VOITLE, R.A.; JANKY, D.M.; WILSON, H.R. The influence of biotin supplementation of broiler hens and foot pad dermatitis in the progeny. Nutrition Reports International, v.19, p.603-606, 1979.

HARNS, R.H.; DAMRON, B.L.; SIMPSOM, C.F. Effect of wet litter and supplemental biotin and/or whey on the production of foot pad dermatitis in broilers. Poultry Science, v.56, p.291-296, 1977.

HASLAM, S. M., BROWN, S.N.; WILKINS, L.J.; KESTIN, S.C.; WARRISS, P.D.; NICOL, C.J. Preliminary study to examine the utility of using foot burn or hick burn to assess aspects of housing conditions for broiler chicken. British Poultry Science, v.47, p.13-18, 2006.

HESS, J.B.; BILGILI, S.F.; PARSON, A.M.; DOWNS, K.M. Influence of completed zinc products on live performance and carcass grade of broilers. Journal of Applied Poultry Research, v.19, p.49-60, 2001.

HESTER, P.Y. The role of environment and management on leg abnormalities in meat type fowl. Poultry Science, v.73, p.904-915, 1994.

KELECOM, P.M. Pododermatite em aves de gaiola. 2008. 27f. Trabalho monográfico (Especialista em Clínica Médica e Cirúrgica de Animais Selvagens e Exóticos) - Universidade de Medicina Veterinária, Universidade Castelo Branco, Rio de Janeiro.

KESTIN, S.C.; SORENSON, P. Different commercial broiler crosses have different susceptibilities to leg weakness. Poultry Science, v.78, p.1085-1090, 1999.

KESTIN, S.C.; GORDON, S.; SU, G.; SORENSEN, P. Relationships in broiler chickens between lameness, liveweight, growth rate and age. Veterinary Record, v.148, p.195$197,2001$.

KIDD, M.T.; FERKET, P.R.; QURESHI, M.A. Zinc metabolism with special reference to its rale in immunity. World's Poultry Science Joumal, v.52, p.309-324, 1996.

KJAER, J.B.; SU, G.; NIELSEN, B.L.; SORENSEN, P. Foot pad dermatitis and hock burn in broiler chickens and degree of inheritance. Poultry Science, v.85, p.1342-1348, 2006.

KLASING, K. Trace minerals. In: KLASING, K. (Ed). Comparative avian nutrition. CAB, California, U.S.A., 1998, p.262-264.

LEESON, S.A. New look at trace mineral nutrition of poultry: can we reduce the environmental burden of poultry manure? In: NUTRITICIONAL BIOTECHNOLOGY IN THE FEED AND FOOD INDUSTRIES. 2003, Proceedings of Alltech's $\mathbf{1 8}^{\text {th }}$ Annual Symposium. Nottingham University Press, UK., 2003. p.125-130.

MALATHI, V.; DEVEGOWDA, G. In vitro evaluation of non starch polysaccharide digestibility of feed ingredients by enzymes. Poultry Science, v.80, p.302-305, 2001.

MARSMAN, G.J., GRUPPEN, H.; VAN DER POEL, A.F.; KWAKKEL, R.P.; VERSTEGEN, M.W.; VORAGEN, A.G. The effect of thermal processing and enzyme treatments of soybean meal on growth performance, ileal nutrient digestibilities, and chyme characteristics in broiler chicks. Poultry Science, v.76, p.864 872, 1997. 
MATHLOUTHI, N.; SAULNIER, L.; QUEMENER, B.; LARBIER, M. Xylanase, $\beta$-glucanase, and other side enzymatic activities have greater effects on the viscosity of several feedstuffs than xylanase and $\beta$-glucanase used alone or in combination. Journal of Agricultural and Food Chemistry, v.50, p.5121-5127, 2002.

MARTLAND, M.F. Ulcerative dermatitis in broiler chickens: The effects of wet litter. Avian Pathology, v.14, p.353-364, 1985.

MARTRENCHAR, A.; MORISSE, J.P.; HUONNIC, D.; COTTE, J.P. Influence of stocking density on some behavioural, physiological and productivity traits of broilers. Veterinary Research, v.28, n.5, p.473-480, 1997.

MARTRENCHAR, A.; BOILLETOT, E.; HUONNIC, D.; POL, F. Risk factors for foot-pad dermatitis in chicken and turkey broilers in France. Preventive Veterinary Medicine, v.52, p.213-326, 2002.

MAYNE, R.K. A review of the etiology and possible causative factors of foot pad dermatitis in growing turkeys and broilers. World's Poultry Science Journal, v.61, p.256-267, 2005.

MAYNE, R.K.; HOCKING, P.M.; ELSE, R.W. Foot pad dermatitis develops at an early age in commercial turkeys. British Poultry Science, v.47, p.36-42, 2006.

MENZIES, F.D., GOODALL, E.A.; McCONAGHY, D.A.; ALCORN, M.J. An update on the epidemiology of contact dermatitis in commercial broilers. Avian Pathology, v.27, n.2, p.174-180, 1997.

MUKRAMI, A.E.; SALEH, E.A.; WATKINS, S.E.; WALDROUP, P.W. Sodium source and level in broiler diets with and without high levels of animal protein. Journal of Applied Poultry Research, v.9, p.53-61, 2000.

MURILLO, M.G.; JENSEN, L.S. Sulfur amino acid requirement and foot pad dermatitis in turkey poults. Poultry Science, v.55, p.554-562, 1975

NAGARAJ, M.; BIGUZZI, F.; HESS, J.B.; BILGILI, S.F. Paw burns in broiler chickens are negatively affected by high protein and all vegetable diets. Poultry Science, v.85 (Suppl.1), p.169-170, 2006 (Abstract).

NOY, Y.; SKLAN, D. Digestion and absorption in the young chicks. Poultry Science, v.73, p.366-373, 1994.

NATION Chicken Council (NRC). Statistics and Research: Per Capita Consumption of Poultry and Livestock (Current as of Sept. 1, 2005) 1960 to Projected 2007 (Estimated by ERS/USDA), 2006.

OLIVEIRA, M.C.; CARVALHO, I.D. Rendimento e lesões em carcaça de frangos de corte criados em diferentes camas e densidades populacionais. Revista Ciência e Agrotecnologia, v.26, n.5, p.1076-1081, 2002.

OLIVEIRA, M.C.; MENDONÇA FILHO, P.R. de; CARVALHO, I.D. Rendimento e lesões em carcaça de frangos de corte sexados criados em diferentes densidades populacionais. ARS Veterinaria, v.20, n.1, p.16-21, 2004.

OLIVEIRA, W.N.K. de; SILVA, J.L.; LUCENA, C.A.L.; SILVA, K.R.L. da; TAKATA, F.N.; EVÊNCIO NETO, J. Uso do zinco orgânico na prevenção de lesões de pododermatite em aves. In: X JORNADA DE ENSINO, PESQUISA E EXTENSÃO - JEPEX 2010, Recife. Anais ... Recife: UFRPE, 2010. 
PAGAZAURTUNDUA, A.; WARRISS, P.D. Levels of foot pad dermatitis in broiler chickens reared in 5 different systems. British Poultry Science, v.47, n.5, p.529-532, 2006.

RUPLEY, A.G. Manual de Clínica Aviária. São Paulo: Roca, 1999.

SAIF, Y.M. Diseases of poultry. $11^{\text {th }}$ edition. Blackwell Publishing Company. Iowa State. U.S.A, 2005.

SANABRIA, R.Z.; MORALES, J.A. Evaluación del efecto del complejo zinc-manganesioaminoacido em pollo de engorde. 2006. 29f. Proyecto de investigación. Escuela de Medicina Veterinaria, Centro de Investigaciones em Nutricion Animal - CINA, Universidad de Costa Rica, Costa Rica.

SANTOS, R.L.; NUNES, V.A.; BAIÃO, N.C. Pododermatite de contato em frangos de corte. Arquivo Brasileiro de Medicina Veterinária e Zootecnia, v.54, n.6, p., 2002

SORENSEN, P.; SU, G.; KESTIN, S.C. Effects of age and stocking density on leg weakness in broiler chickens. Poultry Science, v.79, p.864-870, 2000.

SVEDBERG, J. The connection between environment and foot condition in laying hens. In: $6^{\text {th }}$ INTERNATIONAL CONGRESS ON ANIMAL HYGIENE, 1988. Proceedings ... Skara. 1988. p.125-130.

WANG, G., EKSTRAND, C.; SVEDBERG, J. Wet litter and perches as risk factors for the development of foot pad dermatitis in floor-housed hens. British Poultry Science, v.39, p.191-197, 1998.

WHITEHEAD, C.C.; BANNISTER, D.W. Aspects of metabolism related to the occurrence of skin lesions in biotin-defitient chicks. British Poultry Science, v.22, p.467-472, 1981. 